\title{
6 Are There Expressive Constraints on Incarceration?
}

\author{
Bill Wringe
}

\section{Setting the Scene}

Philosophers' attempts to justify punishment have focused on a wide range of features that paradigmatic cases of punishment possess. The most obvious such features are, of course, punishment's (alleged) capacity for incapacitating wrongdoers and deterring future wrongdoing (Bentham 1907 [1780]; Tadros 2011); and its (alleged) ability to exact from an offender a deserved quantum of suffering (Kant 1996 [1797]). Others include its supposed capacity to handicap the endeavors of those who do not regard themselves as bound by the constraints which bind other members of society (Dagger 1993, 2008), the provision of opportunities for offenders to repent and achieve a measure of moral growth (Duff 1986, 2001), and the feature of punishment with which I shall be most concerned in this chapter, its capacity to, as they say, 'send a message' (Feinberg 1965; Hampton 1992; Duff 1986, 2001).

Those who defend theories of this sort might be expected to have views about the kinds of punishments which their views can and cannot justify. Some of these limitations will be internal to the theory put forward. So, for example, those who defend the institution of punishment on deterrence-based grounds can be expected to argue that their theories only justify punishments up to a level of severity at which trade-offs between deterrent effectiveness and the costs—both direct and indirect—of imposing further punishment moves from positive to negative (Bentham 1907). Other kinds of constraint will be extrinsic to the theory under considerations. For example, someone might hold that there are some forms of treatment which are so cruel and degrading, or so unequal in their effects on those on whom they are imposed, that whatever their deterrent effect or expressive power, we simply should not impose them. ${ }^{1}$

In this chapter I shall be concerned not just with one particular version of expressivism: the 'denunciatory' version of expressivism which I have defended in detail elsewhere (Wringe 2016; Wringe 2017) and in particular with the question of whether this theory generates internal constraints on the kinds of punishment that can justifiably be imposed and if so, what they 
are. I shall argue that there are. Indeed, the internal constraints on permissible forms of punishment which the theory generates are quite substantial: they would rule out the harshening and, in many cases, prescribe the lessening of the severity of many kinds of punishment which existing societies inflict on their citizens.

Advocates of expressive accounts of punishment often claim that their views provide reasons for reducing the severity of penal sanctions. (See, for example, Duff 2001; Lippke 2007). Their views typically differ from mine in a crucial respect. Their arguments focus on the role that punishment plays or can play in communicating with a convicted offender. Those who have views of this sort are well-placed to argue that forms of punishment which undermine the offender's status as a recipient of the appropriate form of communication, or their capacity to respond to that communication in an appropriate way, undermine their own putative justification. Duff, for example, regards punishment as being aimed at communicating with an offender in such a way as to elicit remorse and regret-with the eventual goal being an offender's reintegration into a political community (Duff 2001, as discussed and criticized by Boonin 2008; Hanna 2008; Wringe 2013; Glasgow 2015; Wringe 2016, Wringe 2017). Such remorse and regret would be undermined by treating an offender in ways which undermine their sense of themselves as a moral agent, for regret of the right sort presupposes that one see oneself as such (Cochrane 2017).

By contrast, on the view of punishment which I defend, the primary audience of the form of communication which punishment involves is not the convicted offender, but the political society whose laws have been infringed. One might worry that on this view, the severity of the kind of punishment that can be justified will be limited only by the limits-if any exist—of what will communicate effectively with society at large. Indeed the theory might even be thought to require an increase in the level of severity of punishment in societies which, plausibly, already punish some of their members too much.

I shall argue that matters are less dire than this pessimistic line of thought suggests. Once we attend to the content, as well as the audience, of the messages which punishment ought to express, we find that there are grounds, internal to the theory, for thinking that there are limits to the severity of the kinds of punishment it can justify. Let's see why.

\section{Expressivism-The Very Idea}

Why should we think punishment has an expressive dimension? In a well-known early discussion, Feinberg argues that we can distinguish between a general sense of punishment on which punishment involves "the infliction of hardship by an authority on a person for his prior failing in some respect," and what he calls a "narrow and more emphatic sense," which involves a form of symbolic reprobation which can in principle be absent 
from what Feinberg calls "mere penalties" such as parking tickets (Feinberg 1965: 397-9). He then argues that legal punishment has a number of significant functions, which go beyond deterrence and retribution, and which would be impossible if it did not have a reprobatory aspect. These include the authoritative disavowal of wrongdoing; symbolic non-acquiescence in criminal acts; vindication of the law and absolution of those who are not involved in wrongdoing (Feinberg 1965: 405ff).

Feinberg's talk of the 'functions' of punishment raises many questions. We might ask what is entailed by the claim that a social institution has a certain function, and in virtue of what kinds of facts this is true. Does its truth, if it is true, depend on members of society having certain intentions with respect to punishment? If so, which members of society, and what kind of intentions? Or does Feinberg's claim simply involve an attribution of a function in a sense which has been analyzed by philosophers of cognitive science, biology and medicine? If so, which of these analyses is the relevant one? Is Feinberg's claim to be understood as one about the contributions penal institutions make to the functioning of society as a whole (Cummins 1975), or does it purport to explain the persistence of those institutions in ways which depend on the performance of these functions (Wright 1973)?

These would be urgent questions if Feinberg were interpreted, as he sometimes has been, as appealing to these functions of punishment as ways in which the institution of punishment might be justified. However, Feinberg might be understood slightly differently_as making what we might call a hermeneutic claim. On this interpretation he might be taken as pointing out both that punishment is typically understood in certain ways, and that it can do so only if it involves a certain kind of symbolic act. This interpretation closes off the possibility of a gap between what punishment appears to us to be, and what it really is. If we are talking about actions which are expressive by their very nature, there is no room for a gap between what they are taken to mean by the right kind of interpreters and what they are typically taken to mean, any more than there is room for a gap between what people take the sense of a commonly used phrase to be and what its sense actually is.

This account of Feinberg's position leaves wide open questions about the justification of punishment: questions which have been pressed by David Boonin among others (Boonin 2008). Boonin argues that as a matter of conceptual necessity punishment involves intentionally harming others (Boonin 2008: 12-17). (This claim might be understood as a particular way of interpreting a very widely accepted claim, namely that punishment involves hard treatment.) He then asks how the fact that a certain kind of behavior involves a kind of reprobatory expression could make permissible forms of behavior which we would not otherwise regard as permissible-namely the inflicting of harm on others.

Expressivist conceptions of punishment suggest a way of responding to this challenge. The expressivist should not attempt to argue that the expressive dimension of punishment makes permissible forms of behavior that 


\section{Bill Wringe}

would not otherwise be permissible. Instead, they should note that adopting an expressivist conception of punishment puts us in a position to challenge the characterization of punishment that Boonin gives. Rather than accepting that punishment involves the intentional inflicting of harm, the expressivist can claim that the requirement that punishment involve hard treatment is satisfied provided that penal institutions are of a sort which reliably cause suffering to those who are subjected to them (Wringe 2013). Of course there are ways of treating individuals which reliably cause suffering which we would not typically count as forms of punishment (for example, compulsory psychiatric treatment, pre-trial arrest, self-defense and so on). However, the expressivist can explain - in a way that other kinds of theorist cannot-why these are not forms of punishment: rather than appealing to the intentions with which suffering is inflicted, they can point out that these forms of punishment do not have the kind of expressive role characteristic of punishment (Wringe 2013: 866-8).

\section{Punishment's Audience}

If this expressivist response to Boonin's challenge to the legitimacy of punishment is to be made good, the expressivist needs to give a more detailed account of the expressive role of punishment. Without such an account we cannot assess whether it is plausible to think that forms of behavior which reliably cause suffering but which we do not typically think of as involving punishment lack the expressive dimension that is typical of punishment. We need, specifically, an account of what punishment expresses and who it expresses it to.

First then: what is the audience that punishment expresses its message to? There seem to be three different kinds of answers one might give. In one view, which we might call 'pure expressivism,' the attitudes expressed in punishment need not be expressed to any audience in particular. To express an attitude may simply be to manifest possession of it, in the sense that we use when we talk of a disposition being manifested by its instances. Perhaps a form of behavior can only count as a manifestation of an attitude in this sense if it is in principle capable of being understood as such by some audience or other. But even if this is so, it need not follow that in expressing the attitude, we intend it to be understood by some audience in particular (Glasgow 2015; Bennett 2008).

As Joshua Glasgow has noted, one advantage of a pure expressivist view is that it avoids a problem to which views that think of punishment as involving expression to some particular audience seem susceptible: namely the question of whether punishment ceases to be justifiable if the audience at which it is aimed is unreceptive- that is to say, if it is incapable of understanding the message that punishment is intended to send (Glasgow 2015). However, the pure expressivist view seems implausible. It is hard to see how the manifestation of an attitude to no audience could have a value 
that the mere possession of that attitude would not. (One possible response might be that the possession of the attitude is in some sense constituted by its manifestation. It's implausible to think that the attitudes of individuals are constituted by their manifestation-that way, behaviorism lies. Still we might think that punishment expresses the attitudes of some kind of plural subject or collective agent [Gilbert 2006]. It might be less implausible to adopt a behaviorist stance to attitudes of such subjects. Still, this is a big commitment for the pure expressivist to take on.)

A further weakness of pure expressivism is that it appears to detach the expressivist position from the main considerations to which Feinberg appeals in making the case that punishment properly understood must have an expressive dimension: it is hard to make sense of the notions of authoritative disavowal of wrongdoing; symbolic non-acquiescence in criminal acts; vindication and absolution of those who are not involved in wrongdoing in terms which do not make reference to an audience to whom something is disavowed; in front of whom someone vindicated; and before whom one is absolved.

Pure expressivism also seems to run into trouble when confronted with features of our expressive practice which seem essential to the operation of legal punishment but which is unrelated to pure expression. The point has been made most famously - with reference to the hard treatment of offenders (Feinberg 1965: 419-23). However, it can be as easily made by focusing on something else which seems essential to legal punishment: the fact that it takes place under the eye of the public. By this I mean: the fact that punishments are assigned in publicly accessible courtrooms; that a person is punished and the reasons for which they are punished is a matter of public record; that punishment affects an individual's civic status in various respects; and so on. Many of these features of punishment increase the hardships which punishment entails. On the view that punishment involves a form of expression which is not directed at any particular audience, they are difficult to explain. (One might think that some of these features of punishment serve the purpose of protecting convicted offenders from abuse. However, it seems highly implausible that they do any such thing; and other features of our penal system make it hard to believe that this can be an aim which is any way prominent.)

Antony Duff's 'communicative' version of expressivism (Duff 1986, 2001; see also Falls 1987) might seem to avoid some of the difficulties which pure expressivism faces. For Duff punishment expresses a message to a convicted offender. The point of doing so, on his view, is to encourage (but not coerce) the offender to experience remorse or regret. Duff hopes to explain why punishment needs to involve hard treatment: we might think-though this is an empirical claim, which may have less empirical backing than we might hope for-that either the effective expression of the right kind of message or its expressive uptake will require that it be delivered via the medium of harsh treatment. However, as I have argued elsewhere Duff's theory runs 


\section{Bill Wringe}

into the same difficulties that the pure expressivist faces when accounting for the publicity of punishment (Wringe 2017).

No such problem arises for a third version of expressivism, which I call 'denunciatory expressivism.' On this view punishment expresses a message to a particular audience. The audience is, however, not the offender, but the members of the political community whose laws the convicted offender has broken. It is natural to take Feinberg to have been defending a view of this sort: when we ask the questions 'to whom might we be disavowing wrongdoing; displaying symbolic non-acquiescence; vindicating the law; and in front of whom might we be granting absolution,' the answer might well seem to be 'society at large.' Furthermore, on this view, the public nature of punishment ceases to be mysterious: we cannot hope to express a message to society unless we make it available to them to understand. We may also have an answer to the problem Feinberg raises for his own view as to why punishment should involve harsh treatment: the audience to whom punishment expresses a message may be one which will only take the message in the way in which it needs to be taken if it is expressed via the infliction of harsh treatment. And finally, while there might conceivably be societies which are 'unreceptive' in ways analogous to the ways that offenders can be unreceptive, it seems reasonable to hope that actually existing societies are not.

\section{Does the Denunciatory Account Legitimate Excessive Punishment?}

However, advocates of a denunciatory account of punishment need to address an important objection. On a denunciatory account, the justifiability of punishment as a whole depends on its capacity to communicate messages about the offenses of convicted offenders to society at large. We might think it followed that the justifiability or otherwise of particular forms of punishment will depend to some extent or other on what the members of that society take the expressive significance of those forms of punishment to be.

This gives rise to two kinds of problem. One has to do with relative levels of severity in punishment; the other with absolute levels. ${ }^{2}$ The problem about relative levels of punishment is that it seems as though in more punitively minded societies denunciatory considerations would justify harsher sentences for a given crime than would be justified in a society where such punitive attitudes were less widespread. Given the plausible empirical hypothesis that levels of punitiveness might vary from society to society, one might suspect the denunciatory theorist will end up arguing that in different societies different levels of punishment for the same crime will count as justified. The problem about absolute levels of punishment is that in some societies understandings of the significance of punishment might be so harsh as to justify forms of punishment which would seem excessive 
by any reasonable standard (let alone, for example, the standards of 8 th Amendment jurisprudence in the United States.)

How serious is the first problem? Perhaps there is nothing especially surprising about the idea that the severity with which certain crimes are punished should vary from place to place, and nothing objectionable-but rather the reverse-about a theory which explained why this might be justifiable. Still we might think that while levels of punitive severity do vary from place to place, we can appropriately criticize the ways in which individuals are punished in one society by comparing their treatment with the treatment of similar offenders elsewhere. ${ }^{3}$ The denunciatory account runs the risk of ruling this kind of criticism inadmissible.

However, the problem about absolute levels of severity seems even more serious. For we might think that there are a range of levels of severity with which any given crime might justifiably be punished, and that societies could justifiably set sentences for a given crime at any of the range of levels within that acceptable range for a variety of public policy-related reasons. Considerations about the ways in which punishments would be understood might then be one factor which could legitimately feature in the determination of appropriate levels of severity in punishment. By contrast, if the denunciatory theory turned out to require levels of punishment which were unacceptable for reasons which were independent of cross-society comparisons, no analogous response would be available.

Could a denunciatory theory require punishments of a level that we might otherwise regard as unacceptably harsh? Popular responses to penal policy in various countries might make us pessimistic. There is considerable evidence that in many countries existing penal policies are seen as being too lenient; that proposals to lengthen sentences or to increase their severity are popular with electorates; and that by the same token proposals for sentence reduction tend to be electorally unpopular (Bottoms 1995; Pratt 2007). However, there is also some evidence that support for more severe sentencing policies often reflects mistaken views about what kinds of sentencing policy are in effect, and that the most spectacular instances of overly penal attitudes seem to reflect a considerable degree of misinformation about the levels of punishment prevalent within a given society (Dzur 2012). If so, then instead of providing reasons for increasing the severity of punishments imposed on convicted offenders, the denunciatory account might support a case for more effective programs of civic education in order to ensure that the messages punishment is intended to send are successfully conveyed to the audience the theory says they are directed to. ${ }^{4}$

Someone might think a denunciatory theorist of punishment cannot face a serious objection here. They might argue as follows. Either there are constraints on the way in which we can legitimately treat people when we punish them that exist for reasons which are independent of a denunciatory account of punishment or there are not. If there are not, then it cannot be true that the denunciatory theory legitimates forms of punishment which we 


\section{Bill Wringe}

have independent reason for taking to be unacceptable. But if there are-as most people would no doubt accept - then we already have an explanation of why certain forms of punishment which the denunciatory theory would appear to legitimate cannot in fact be regarded as legitimate. They are illegitimate precisely because they violate these independent constraints.

However this line of argument seems unsatisfactory. The denunciatory theory of punishment is supposed to explain how some forms of punishment could be legitimate. Although we need not think that it needs not show that the forms of punishment prevalent in existing societies must be justified, we should nevertheless expect them to show that in such societies some form of punishment is justified. An account which appeals to external constraints on the ways in which we can treat people in order to explain why certain forms of apparently excessive punishment are not legitimate might not meet this constraint. For the minimum level of severity required by the denunciatory account might turn out to be greater than the maximum level of severity permitted by the external constraints.

\section{Expressive Limits on Punishment (1)}

So far I have argued that we have reason to worry that a denunciatory theory of punishment might legitimate unacceptably severe forms of punishment. I have also argued that addressing this worry by appealing to the existence of external constraints on the acceptability of levels of punishment risks leaving us without an account of how any form of punishment could be justified. I shall now argue that there are significant internal constraints on the kinds of punishment which the denunciatory theory could legitimate. To see what these limits are we need to consider the content of the message we should take (justified) punishment to convey.

Some expressive theorists of punishment have addressed this issue. Feinberg (1965: 403) writes that punishment involves "a kind of fusing of resentment and reprobation" where resentment is supposed to be a placeholder term for a variety of vengeful attitudes and reprobation involves a stern judgment of disapproval; and Nozick (1981), who finds little room for the idea that punishment incorporates any kind of vengeful attitude, develops the idea of a stern judgment of disapproval in such a way as to accommodate the thought that different degrees of punishment will presumably convey different messages and argues that the messages that punishment conveys will typically be of the form 'this is how wrong you were.' There is nonetheless a dearth of arguments for taking the expressive content of punishment to be one thing rather than another.

Elsewhere I have argued that a denunciatory theorist of punishment should argue that the message expressed in punishment have the following form: "Offender $\mathrm{X}$ has committed an act of type $\mathrm{T}$ and in doing so they have acted wrongly" (Wringe 2016). I have also argued that in order to understand this form of communication in a way that does not endow the 
state with an inappropriate and unjustifiable kind of moral authority, it is important to take it to be one which takes place between a collective agent and its members, and to take the particular kind of wrongdoing involved to be that of an individual's reneging on their part in a collective commitment (Wringe 2016: Chapter 3). I shall not recapitulate my arguments for this formulation in detail here. ${ }^{5}$ Instead I shall argue that the idea that punishment is supposed to convey a content of precisely this sort places limits on the forms of harsh treatment which might be used to express it. I suggest that it gives rise to two non-trivial forms of constraint of precisely this sort. One arises from the fact that the punishment is intended to convey that a certain kind of action is wrong; the second form, the kind of wrongness which is intended to be conveyed.

Let us start with the idea that the denunciatory content of punitive hard treatment is supposed to convey that the convicted offender has done something wrong. We might regard it as a condition of having done something wrong-as opposed to, say, unfortunate or destructive-that they be regarded as culpable. Whatever the conditions for culpability are, they must surely include being a responsible moral agent. If so, then forms of treatment which convey to society at large that individuals are not responsible moral agents would seem to be ruled out (or would at least require some form of moral justification).

Could any conceivable forms of punishment convey such a message? It is possible to imagine some that might. A form of (supposed) punishment might, for example, require someone convicted of a crime of violence to wear a billboard with the message 'I am a dangerous animal.' So the denunciatory account seems to place at least some constraints on the forms that punishment properly so-called might take. But these constraints might seem relatively unimpressive. We might wonder whether the theory rules out any forms of treatment that are carried out with regularity in existing penal systems.

We might think that some ways in which offenders are treated are designed to convey to offenders themselves that they are not fully responsible agents. Restrictions on relatively trivial matters of personal choice-such as clothing and hair-style-might count here. So, conceivably, might some of the conditions of confinement in so-called Supermax prisons (cf. Lippke 2004). However, this line of argument does not necessarily establish the conclusion we are searching for. Conveying something about an offender is a different matter from conveying it to society at large: indeed, the distinction I drew earlier between denunciatory and communicative forms of punishment depends on precisely this point. Furthermore, we might think that since many of the features of prison life which appear to convey these messages are not widely known or even widely publicized, they cannot count as intended to convey a message to society at large. We might also worry that insofar as this argument makes substantial claims on the limits that might be placed on justifiable conditions of confinement, it blurs the distinction 


\section{Bill Wringe}

between a form of treatment's reliably having certain kinds of effects and its being intended to communicate something about an offender. The fact that Supermax prisons undermine individuals' capacities for agency need not entail that imprisoning individuals under Supermax conditions communicates any kind of message that they are not agents.

One response to the first of these points might be that the plausibility of a denunciatory theory of punishment should not depend on the public at large having a detailed knowledge of the exact treatment of particular offenders. The existence of widely available representations-in film, fiction, and the news-can be regarded as establishing that certain forms of treatment have a widely understood cultural meaning; and the fact that it is possible for members of the public to learn that offenders have been treated in a certain way might be thought to do enough to make sure that punishment send a particular message about those particular offenders to anyone who is alert to it.

However, a different response seems more promising. Suppose we grant that details of the conditions of confinement of convicted offenders are not widely known beyond prison walls. There are, nevertheless, some parts of society to whom they are well known. Prison staff fall into this category; as do law enforcement officials. And so do other offenders. For, as I have already suggested, it is an important feature of punishment that can be justified by denunciatory methods that it convey the message that those who are punished are members of society.

What about the worry that the argument put forward so far merely undermines-in a strictly causal sense-the agency of convicted offenders, without necessarily being intended to undermine-in any justificatory sense-a claim to the effect that they are agents? We might simply say that in practice certain kinds of incarcerative practice do both: they inhibit agency, and they inhibit our capacity to see those on whom they are inflicted as agents. Still, an objector might insist that this is no part of what such conditions are intended to convey. If we think, as Nozick did, that the content of penal communication depends on the right kind of Gricean communicative intention, the worry still stands (Nozick 1980; Grice 1957; Wringe 2016). Or we might say that although a sensitive genealogical analysis of the history of these forms of incarcerative practice shows them to bear the trace of intentions of the right (or wrong) sort, we can also imagine practices with a different history, but the same kinds of effects, and that it would be highly counterintuitive to think that a practice of this sort could fail to be objectionable if our actual practice is objectionable.

Could there be other ways in which punishments which undermine an offender's capacity for agency might be regarded as objectionable from the denunciatory point of view? Perhaps the existence of conditions of confinement which undermine a prisoner's capacity for agency make it harder for the intended audience to grasp the message that punishment is supposed to convey. One weakness in this line of argument is that it seems to be 
undermined by concessions already made. If we have accepted that a form of punishment may be justified by denunciatory means even if knowledge of its application is not especially widespread, then it is unclear why a justification of this sort should be undermined by the fact that the form of punishment chosen is not an especially effective means of conveying the relevant kind of message. Furthermore we might think that the ways in which inappropriate treatment of convicted offenders might undermine the effectiveness of the message that punishment is supposed to convey could be remedied by other measures.

A more promising suggestion is that forms of punishment which undermine the agential capacities of convicted offenders are pragmatically self-defeating. In general, pragmatic self-defeat occurs when the way in which a message is conveyed to its intended audience undermines the credibility of that message. Consider someone who asserts, in perfect English, that they speak no English at all. From a logical point of view, there is nothing amiss with the content of their assertion: there is nothing in the existence of someone who speaks no English that contravenes the laws of logic. Nevertheless, that particular message cannot be conveyed in that particular way. Other examples can be given: consider someone asserting that they make no assertions at all; and so on. The denunciatory theorist might argue analogously, that treating someone in ways which undermine their capacities for agency involves pragmatic self-defeat of precisely this sort.

One might worry that this argument proves too much. It might appear to rule out the possibility of any form of confinement being used as a form of punishment. For one might think that any form of confinement impinges on an individual's capacity for agency in a negative manner. So we might think that the denunciatory theorist entails that, that no form of confinement can be an acceptable form of punishment. Some might welcome this corollary; but others will no doubt regard it as a reductio of the denunciatory view. However, I do not think it need be either. These cases of pragmatic self-defeat which I used to introduce the view suggest that pragmatic self-defeat is an all-or-nothing affair. However, it need not be. Consider someone who says in fluent, well-accented English, that they speak almost no English. The truth of what they say is not incompatible with their having said it. Nevertheless, their utterance seems closely analogous to the more obvious cases of pragmatic self-defeat we have already considered. We might understand agency undermining form of punitive practice in a similar way.

\section{Expressive Limits on Punishment (2)}

The arguments of Section 5 suggested that the content of penal communication might place significant constraints on the kinds of punishment that might be acceptable. Now I wish to explore the idea, broached in Section 4, that further constraints stem from the fact that offenders are part of the audience for penal communications. 


\section{Bill Wringe}

We might think that the fact that the intended audience of penal communication includes the offender precludes the possibility of using expressive means which exclude the offender from membership of that community. Suppose this were correct. What, if anything, might it rule out? One obvious possibility is exile. Some might regard this as a historical curiosity (but see McGinnis, this volume). Nevertheless it seems significant that exile is a form of treatment which is ruled out as a form of punishment on conceptual, and not merely pragmatic, grounds. (Another example which shares some of the features of exile might be excommunication. We might regard this as a marginal case in a discussion of state punishment; but in the light of Duff's suggestion that we understand punishment as involving a kind of "secular penance" it seems worth noting [Duff 2001:106-30].)

We might think that the disenfranchisement of discharged felons is also ruled out. For it might seem that in disenfranchising members of a democratic society, we are both excluding them from full membership of society, and communicating to society at large that they are so disqualified. Some might argue that felon disenfranchisement is not a punishment, strictly so called, but rather a civil disqualification. However, it seems plausible that on the communicative view of punishment defended in Section 2, post-release disenfranchisement should be counted as a form punishment. It is less clear that the same can be said of the disenfranchisement of convicted criminals during a limited period of punitive imprisonment. For loss of the franchise during a period of temporary imprisonment would at best be expressive of temporary exclusion from a political community. So those who wish to argue that prisoners should have the right to vote should do so on other grounds.

The requirement that punishment be addressed to an offender qua member of a political community might rule out considerably more than this. We might think that the requirement rules out very long periods of incarceration, including, but perhaps not limited to, lifelong incarceration. Those who are imprisoned for the rest of their lives might be regarded as being permanently excluded from the political community; and those who are imprisoned for very long terms might be regarded as effectively precluded from effective future membership of a political community, given what we know about the marginalizing effects of long-term confinement. We might also regard many of the standard conditions of confinement imposed on convicted offenders as excluding them from the political community. I have in mind here in particular restrictions on prisoners' freedom to associate and to undertake paid work. Someone might suggest that any form of imprisonment worthy of the name must incorporate these features; but work by Richard Lippke (among others) suggests that we should regard these as merely contingent-and undesirable-features of imprisonment (Lippke 2007). (We might also note that to the extent that these cease to be features of imprisonment, the case for thinking that expressive constraints on imprisonment rule out long-term imprisonment will be weakened.) 
Someone might wonder whether these conditions can be regarded as central to membership in a political community. They might do so on the basis of a relatively narrow understanding of the domain of the political, as encompassing only those kinds of activities which are covered in the 'political' sections of national newspapers: for example, voting in elections, participating in electoral campaigns, and so on. Still we might think that this draws the limits of the political too narrowly. A broader conception might start from Aristotle's conception of human beings as 'political animals,' where the political might be understood as encompassing those activities which are characteristic of human beings living in self-governing groups. What is characteristic of such beings is-at least as Aristotle seems to conceive of it - a capacity for engaging in self-directed activity with a collective dimension (Schmid 2016).

If we understand membership in a political community in this way then the range of potential expressive constraints on incarceration will be considerably expanded. But we might think that their strength will be decreased. Consider the mooted argument against felon disenfranchisement. Expanding the scope of the political seems to leave open the possibility that someone who was excluded from the vote might still be a member of the political community in a broader sense. This might be an argument against the broader view. But it need not be. It does suggest that a case against felon disenfranchisement might need to be made on other kinds of grounds. But a number of authors have explored just such possibilities (Cochrane 2017; Bennett 2008).

\section{Some Objections Considered}

One might wonder to what extent the view I have outlined here represents a distinctively denunciatory version of an expressive approach to the idea of limits on incarceration. Insofar as arguments for those limits stem from a conception of an offender as a member of a political community, they are likely to be capable of being endorsed by someone who understands the expressive dimension of punishment along communicative, rather than denunciatory, grounds. On communicative theories, punishment is understood as a communication addressed to an offender. Considerations about what makes for effective communication to such an offender might be appealed to by someone who thinks the primary purpose of punishment is communicative rather than denunciatory.

This need not be an objection to my position. I set out to show that denunciatory accounts need not be vulnerable to the charge of justifying excessive penal harshness. I did not set out to show that they were unique in providing grounds for avoiding such harshness. Indeed, anyone who is concerned with reducing the harm done by incarceration ought to hope that they are not. They ought to hope that arguments in favor of harshness can 


\section{Bill Wringe}

be justified on a variety of different grounds, corresponding to different possible justifications of punishment.

Nevertheless, there does seem to be something distinctive about the denunciatory view that I have set out here. It seems to require a certain kind of transparency in the operation of our penal institutions. On a (purely) communicative view we might be content with penal practices that took place out of the public eye. Provided that they served the goals of effective communication with offenders well, and provided that publicity was not required for effective oversight to prevent abuse of penal institutions, the average law-abiding citizen might be justified in being- more or less indifferent to what goes on in penal institutions. On the denunciatory account such indifference seems harder to justify.

This seems like a consideration-albeit a fairly minor one-in favor of preferring a denunciatory version of an expressivist account of how expressive constraints on incarceration might be justified to a communicative one. A view which builds a requirement of transparency into the basis of our account of the kinds of punishment that can be justified seems attractive. But this advantage brings with it a corresponding drawback.

Any account of legal punishment needs to provide some kind of account of the justifiability of punishing those who are not members of the political community whose rules they have transgressed. For almost everyone thinks that the punishment of visiting foreigners and of non-resident aliens can be justified. Denunciatory theorists of punishment have fewer problems in accounting for this familiar fact than many of their rivals. For there is no reason why the punishment of those who are not members of a given community should not play the same denunciatory role as the punishment of members.

However, the denunciatory theorist does seem to face a problem when we consider the existence of expressive constraints on acceptable forms of punishment. For it seems intuitively appealing to suppose that if such constraints exist, they would apply in the same kinds of way to anyone the state punishes: and in particular to foreigners and non-resident aliens as much as to anyone else. But the denunciatory account that I have put forward here seems unable to explain why this should be so. The constraints were explained on the supposition that those who were punished were part of the intended audience of penal communication; that they were, in other words, part of the political community.

It is worth considering two different kinds of non-member. One will be slightly surprising. Consider corporate entities. They are not themselves members of a political community (though their members typically will be). It doesn't seem at all implausible to think that constraints on the punishment of individual community members might not be applicable to the punishment of corporations. ${ }^{6}$ For example, it might be permissible to respond to corporate wrongdoing by undermining or destroying the agency of the corporate 
agent, provided this did not constitute unjustified punishment of, or in any other way infringe the rights of, any individuals (see Wringe 2012, 2016).

The punishment of individuals who are not members of a given society presents a more difficult case. The denunciatory theorist might regard resident aliens (and perhaps even visitors) as having a kind of temporary membership of a political society (continued at least as long as they are imprisoned). Expanding the domain of the political, along lines I have suggested above, may make this strategy attractive. Alternatively, we might appeal to considerations of proportionality to rule out the possibility of non-citizens being punished more severely than citizens for the very same offenses.

One final objection might arise with respect to those who might be regarded by their actions as having put themselves outside the political community. Aristotle says of those that live outside a political community that they must be either a monster or a god.7 We may not have any gods living among us, but some might think we have some monsters. I am not so sure. But there does seem to be one thing we can say. This is that even if some people do put themselves outside the political community, considerations of proportionality will still dictate that, if they commit the same crimes as non-monsters, their punishments need to be constrained in the same way. Only if we think that there are monstrous crimes, and not merely monstrous criminals, will we reach a case where the arguments of this paper do not apply.

\section{Notes}

1 As did the authors of the American constitution, for example.

2 Talk of 'levels' of severity may suggest, misleadingly, that there's only one dimension along which punishments may vary in respect of their severity. I doubt there is. However, all that's required for my argument is that some sentences can be compared with other sentences in their degree of harshness. There's little reason to be skeptical of this less ambitious claim.

3 Theories which incorporate a (general) deterrence-based element may face a similar problem here. For on such theories the justifiable level of punishment will depend on considerations such as how easily other offenders in a given society are deterred from committing similar crimes; how widespread knowledge of the levels of punishment to which particular individuals are subjected really is; and so on.

4 We might also take heart from Dzur's (2012) interesting work on jury participation, which suggests that the prevalence of punitive attitudes among society as a whole might be reduced by increasing the degree to which members of the public participate in the judicial system as jury members and so on,

5 But see Wringe 2016, Chapter 3

6 Note that there will be those who think that it makes no sense to think of collective agents being punished, since they cannot suffer (Rich 2015). However, I do not agree that punishment is an essential element of suffering for reasons given in Wringe 2013. For further defense of this view about the relationship between punishment and suffering see Poama 2016; Coverdale 2013.

7 Aristotle 1981: 1253a1. 


\section{Bill Wringe}

\section{References}

Aristotle (1981). Politics, trans. J. Saunders Trevor. London: Penguin.

Bennett, Christopher. (2008). The Apology Ritual. Cambridge: Cambridge University Press.

Bentham, Jeremy. (1907). An Introduction to the Principles of Morals and Legislation. Oxford: Clarendon Press.

Boonin, David. (2008). The Problem of Punishment. Cambridge: Cambridge University Press.

Bottoms, Anthony E. (1995). "The Philosophy and Politics of Punishment and Sentencing." In The Politics of Sentencing Reform, ed. C. Clarkson and R. Morgan. Oxford: Oxford University Press.

Cochrane Alasdair. (2017). "Prison on Appeal: The Idea of Communicative Incarceration." Criminal Law and Philosophy 11: 295-312

Coverdale, Helen. (2013). "Punishing with Care: Treating Offenders as Equal Persons in Criminal Punishment." Unpublished Ph.D. Thesis, London School of Economics. Available at http://ww.etheses.lse.ac.uk/1080/.

Cummins, Robert (1975). “Functional Analysis.” Journal of Philosophy 72: 741-64.

Dagger, Richard (1993). "Playing Fair with Punishment." Ethics 103: 473-88.

Dagger, Richard (2008). "Punishment as Fair Play." Res Publica 14: 259-75.

Duff, R.Antony(1986). Trials and Punishments. Cambridge: Cambridge University Press.

Duff, R.Antony (2001). Punishment, Communication and Community. Cambridge: Cambridge University Press.

Dzur, Albert (2012). Punishment, Participatory Democracy, and the Jury. Oxford: Oxford University Press.

Falls, Margaret M. (1987). "Retribution, Reciprocity, and Respect for Persons." Law and Philosophy 6: 25-51.

Feinberg, Joel (1965). "The Expressive Function of Punishment." The Monist 49: 397-423, reprinted in Doing and Deserving, Princeton, NJ: Princeton University Press.

Gilbert, Margaret (2006). A Theory of Political Obligation: Membership Commitment and the Bonds of Society. Oxford: Oxford University Press.

Glasgow, Joshua (2015). "The Expressive Theory of Punishment Defended." Law and Philosophy 34: 601-31.

Grice, H. Paul (1957). “Meaning.” Philosophical Review 66: 377-88.

Hampton, Jean (1992). "Correcting Harms Versus Righting Wrongs: The Goal of Retribution." UCLA Law Review 39: 1659-702.

Hanna, Nathan (2008). "Say What? A Critique of Expressive Retributivism." Law and Philosophy 27: 123-50.

Kant, Immanuel (1996). The Metaphysics of Morals, trans. M. McGregor and R. Sullivan. Cambridge: Cambridge University Press.

Lippke, Richard (2004). "Against Supermax." Journal of Applied Philosophy 21: 109-24.

Lippke, Richard (2007). Rethinking Imprisonment. Oxford: Oxford University Press.

Nozick, Robert (1981). Philosophical Explanations. Boston, MA: Harvard University Press.

Poama, Andrei (2015). "Punishment Without Pain: Outline for a Non-Afflictive Definition of Legal Punishment." Philosophy and Public Issues 5: 97-134. 
Pratt, John. (2007). Penal Populism. London: Routledge.

Rich, Sylvia (2016). "Corporate Criminals and Punishment Theory." Canadian Journal of Law \& Jurisprudence 29: 97-118.

Schmid, Hans-Bernard (2016). "Being Well Together: Aristotle on Joint Activity, Plural Self-Awareness, and Common Sense." Proceedings of the 37th International Wittgenstein Symposium, Berlin, De Gruyter. 295-312

Tadros, Victor (2011). The Ends of Harm: The Moral Foundations of Criminal Law. Oxford: Oxford University Press.

Wright, Larry (1973). “Functions.” Philosophical Review 82:139-68.

Wringe, Bill (2012). "Collective Agents and Communicative Theories of Punishment." Journal of Social Philosophy 43: 436-56.

Wringe, Bill (2013). "Must Punishment Be Intended to Cause Suffering?" Ethical Theory and Moral Practice 16: 863-77.

Wringe, Bill (2016). An Expressive Theory of Punishment. London: Palgrave MacMillan.

Wringe, Bill (2017). "Rethinking Expressive Theories of Punishment.” Philosophical Studies 174: 681-708. 